\title{
Social Media and Eating Disorder Psychopathology: A Systematic Review
}

\author{
Paula Friero Padín, Rubén González-Rodríguez, Carmen Verde-Diego, \& Raquel Vázquez-Pérez \\ Department of Psycho-socio-educational Analysis and Intervention, University de Vigo, Ourense, Spain
}

\begin{abstract}
The relationship between socialization through social media (SM) and eating disorders (EDs) is a serious problem for public health, largely affecting the mental health of younger people. This work aimed to identify scientific works addressing ED psychopathologies, studying their relationship with SM usage. In this systematic review, we analyze the available scientific evidence, thereby providing tools for intervention, prevention, and treatment. A systematic review and PRISMA analysis of narrative syntheses was carried out. Works were selected from the databases of Web of Science, Scopus, PubMed, and PsycINFO. Out of a total of 257 references, 19 articles were identified and selected; among them, correlational studies predominated. A growing interest in the subject matter was identified, as it is undergoing constant changes. The investigations found that EDs and SM usage are influenced by the time spent on SM, the type of interactions, and shared photographs, as well as gender and sociocultural context.
\end{abstract}

Keywords: Systematic review; eating disorder psychopathology; social media; anorexia; bulimia

\section{Introduction}

Research on the psychological implications of the use of and exposure to social media (SM) is an area that is gaining momentum and reveals an unmet need due to the rapid increase in mental illnesses linked to SM usage, which poses a threat to public health (Ljungberg et al., 2020). The use of SM at the beginning of the advent of the Internet provoked suspicions among experts who predicted risks to users' well-being. This consideration was subsequently nuanced, as mixed evidence has emerged; that is, the use of SM is beneficial when employed to create meaningful social connections, but harmful in situations such as isolation and social comparison (Clark et al., 2018). Although SM are designed to promote social connection and interaction, many SM users engage in passive utilization, rarely interacting with others' content (Quiroz \& Mickelson, 2021). Thus, among passive SM users - though not limited to them- no interpersonal connections are generated, fostering conditions of isolation and social comparison, which influence personal well-being (Clark et al., 2018). These situations can lead to dissatisfaction in people's self-perception, which can result in efforts to "improve," for example, through restrictive diets and excessive exercise, typical symptoms of some eating disorders (Rodgers, 2016).

The literature that studies the connection between SM and ED psychopathologies is their initial development. Hence, this work aims to carry out a systematic review addressing the currently available research in the area, thus contributing to the development of a solid knowledge base on the subject. By comprehending this topic, mental health professionals can identify unhealthy behaviors, such as high-usage SM time or the kind of shared images that promote disordered eating attitudes and behaviors (Šmahelová et al., 2019). 


\section{Eating Disorder Psychopathology and Concern for Body Image}

EDs have been recognized for centuries, with the first clinical description of anorexia nervosa in 1689 by Richard Morton, and the coining of the term by William Gull at the end of the nineteenth century (Black \& Grant, 2014). In these disorders, unlike almost any other mental health pathology, sociocultural factors contribute notably to their etiology (Black \& Grant, 2014; Schaumberg et al., 2017) although it has been shown that genes also play an important role. Body dissatisfaction among young women has been shown to precede the development of EDs, and it is a consistent and robust predictor (Stice et al., 2011).

The present study focuses on the approach to anorexia nervosa and bulimia nervosa. Following the criteria determined by the American Psychiatric Association (APA, 2013), anorexia and bulimia are the EDs in which occurs a fear of weight gain, as well as an alteration in the self-assessment of the body itself. In this sense, this work includes subclinical EDs, which have a higher prevalence rate than diagnosed EDs (Loth et al., 2014). In ED psychopathologies, body dissatisfaction, negative or altered body image, and eating disorders represent a broad spectrum of food concerns, which are precursors to the development of anorexia and bulimia (Hilbert et al., 2014).

Anorexia nervosa and bulimia nervosa are serious psychiatric diseases with substantial morbidity, and much of the mortality rate is attributable to medical complications inherent to their evolution (Westmoreland et al., 2016). In the review of Chesney et al. (2014), the authors identified a high mortality rate for people with anorexia nervosa, which decreases their life expectancy by 10 to 20 years. Suicide is the second leading cause of death among people with anorexia and also poses a risk among those diagnosed with bulimia nervosa (Goldstein \& Gvion, 2019). Besides, anorexia, bulimia nervosa, and binge eating are difficult to treat and constitute a clear public health problem (Napolitano et al., 2019).

The concept of body image has been studied in different disciplines, including psychology, psychiatry, medicine, and sociology, making the different perspectives essential to explain the alterations of body image and EDs (Blood, 2005). Body image has been defined as a person's perceptions, thoughts, and feelings about their body (Grogan, 2016). In this line, Schilder (1950) argued that it is not only a perceptual construction of one's body but also a reflection of attitudes and interactions with others. Perceptual body image, that is, the accuracy of body-size estimation relative to actual size, is distinguished from attitudinal body image, which is evaluated by four measurements: global subjective satisfaction, affect and feelings, cognitions, and behaviors (Thompson et al., 2012).

Concerning the sociocultural influence of EDs, diagnostic problems in anorexia and bulimia have been shown to be related to culture because, although they occur in diverse populations, the evidence currently suggests a transcultural variation in their development and presentation. Anorexia is most prevalent in high-income postindustrialized countries, such as the United States, many European countries, Australia, New Zealand, and Japan. Its prevalence is comparatively lower among the Latino, African-American, and Asian populations in the United States, which may be biased because of the lower use of mental health services by this population. In terms of bulimia, diagnosis is also prevalent in industrialized countries (United States, Canada, many European countries, Australia, Japan, New Zealand, and South Africa). In clinical studies of bulimia nervosa in the United States, people with bulimia are mainly white women (APA, 2013).

Sociocultural influences have identified that black women may have greater acceptance of a variety of body types and a broader understanding of "beauty" comprising different body sizes (Howard et al., 2017). However, as different Asian countries have become industrialized and globalized, the gap in the amount of EDs between Asia and the West has declined (Soh \& Walter, 2013). Even in Asian countries where EDs were believed to be less prevalent than in the West, comparative studies have emerged documenting food attitudes and levels of body dissatisfaction that are similar or worse than those reported in Western countries (Pike \& Dunne, 2015).

\section{Use of the Social Media}

Concerning SM usage, for many people, it is a daily activity (Gruzd et al., 2018) and constitutes a new virtual scenario that potentially influences the psychological and social development of younger people (American Academy of Pediatrics, 2016). Studying the performance of this activity is a complex reality that goes beyond 
evaluating the time spent on SM by young people (Pertegal-Vega et al., 2019). Furthermore, it is not currently possible to establish a relationship between the number of hours spent on SM and problematic use of the Internet. However, there is evidence that problematic use of SM leads to a decrease in real-life, social community participation, and academic achievement, as well as to relationship problems, all of which may be indicative of potential addiction (American Academy of Pediatrics, 2016).

There is a wide range of content generated and disseminated via SM, including entertainment, communication, and knowledge pertaining to various subjects (Gündüz, 2017). Some of the essential features inherent in different SM are that they are interactive and that the user generates content using text, images, or videos. SM also create specific profiles that make it easier to connect with other people or organizations and in which one's content is grouped (Tao et al., 2016). This systematic review focuses on the most widespread SM platforms, such as Facebook, Instagram, and Twitter, where sharing photos about one's physique and personal appearance is habitual. These SM may contain different comparison objectives or different characteristics that influence physical comparisons (Fardouly et al., 2017). The use of SM involves interaction with people who are well-known in real life, rather than with fictional images, and it can influence the peer competition generated by such exposures (Ferguson et al., 2014). In addition to competing with peers, people may also aspire to be like celebrities and influencers without realizing that they, too, use beauty filters and edited pictures on SM to present an ideal aesthetic (Hendrickse et al., 2017).

In 2021, the global SM penetration rate reached 53.6\% (Statista, 2021). In Western Europe, its usage rate was at $79 \%$, followed by North America at 74\%, and Central America with a usage percentage of $71 \%$. In Southeast Asia, the percentage was $69 \%$ and in Oceania, 64\% (Statista, 2021). The lowest figures were on the African continent but there were notable differences: in the north, $45 \%$ of the population uses SM whereas, in Central Africa, only $8 \%$ of the people use SM, the lowest regional proportion in the world (Statista, 2021). Among the youngest, 16 to 24 years old, nearly 9 out of 10 people in the EU participate in SM (88\%). In Europe, taking into account the population between 16 and 74 years old, SM usage went from 36\% in 2011 to 54\% in 2019 (Eurostat, 2020). Globally, the SM platform with the highest number of users, among whom interaction through photographs predominates, are Facebook (2.449 million), WhatsApp (2 billion), Youtube (2 billion), Instagram (1 billion), and TikTok (800 million) (Statista, 2020).

\section{Involvement of Social Media in Body Dissatisfaction and Eating Disorder Psychopathology}

The negative image of one's body, in particular body dissatisfaction, is highly prevalent among young women (Fallon et al., 2014). Various studies have shown that the use of and exposure to SM generate body image concerns as well the development of EDs (Holland \& Tiggemann, 2016). In this sense, eating disorders are etiologically related to the internalization of social pressure resulting from the standards of feminine beauty of modern industrial society or the Western culture (Stice et al., 2011). The dissemination of these extended aesthetic models on SM creates a risk for the development and maintenance of health problems, as in the case of EDs (Grabe et al., 2008). To this is added that the social comparison on SM generates body dissatisfaction in users when they realize that they cannot achieve the generalized thin ideal (Frederick et al., 2017).

It has been shown that the visualization and exposure to attractive peers through SM contributes to the development of a negative body image (Hogue \& Mills, 2019; Kim, 2020), together with the photographic selfretouching performed by SM users (Mills et al., 2018). SM images are powerful tools not only for communicating but also for perpetuating ideals that influence adolescents' sense of identity. Even when not maliciously intended, images displayed on SM can increase the risk of significant negative consequences in all areas of emotional, mental, and physical health, including an increased risk of EDs and mood disorders (Kwon, 2020). The use of SM combines two influences, on the one hand, the media and, on the other hand, group pressure, promoting a negative body image and requiring social-health intervention and prevention programs for possible EDs (Mabe et al., 2014).

To the social media exposure itself are added the dynamics of interaction through "likes" and comments received on the shared photographs, issues that must be present for our comprehension of ED psychopathologies (Tiggemann et al., 2018). Also, visual images of the SM tend to show carefully selected and retouched photographs. Therefore, it is common for users of SM like Facebook to believe that other people are happier and more 
successful than they are (Hou et al., 2019). Being critical of SM content, having high self-esteem, and a lower tendency to engage in social comparisons buffers the effect of SM on body satisfaction (Brichacek et al., 2018).

Due to all of the above, research has been carried out addressing the relationship between the general use of SM and eating behaviors and even with the development of EDs. To our knowledge, the present study offers the first systematic review of the investigations that correlate both objects of study, SM and ED psychopathologies. Although we are aware of the existence of a systematic review that relates the use of SM to body image, it does not establish as a requirement the inclusion of at least one measure of EDs (Holland \& Tiggemann, 2016).

\section{Research Question}

To support this systematic review, the PECO method was used, which promotes the selection of firm search criteria that facilitate the research question (R. L. Morgan et al., 2018). The acronym for this method corresponds to Population, Exposure, Comparator, and Outcome (R. L. Morgan et al., 2018). Thus, the PECO outline of this study was formulated as follows; P: Among the population using SM, what is the effect of; E: exposure to SM image content versus; C: make more limited use of SM; O: preventing ED psychopathologies. From the PECO and the theoretical aspects set out in the introduction, the research question could be developed: Can the population using SM be affected by its content, influencing the development of ED psychopathologies?

\section{Method}

\section{Search Strategy}

In this study, the analysis of the literature was carried out through a systematic review following the PRISMA standards related to methodological design: protocol, search process, selection, and synthesis of results (Moher et al., 2009). This methodology was used to identify the largest possible number of studies on SM that include measurement and evaluation or diagnosis of EDs. The methodological decisions made were reflected in an ad hoc designed protocol.

The search was conducted between December 2019 and January 2020, identifying empirical research of an essentially quantitative nature from the following databases: Web of Science, Scopus, PubMed, and PsycINFO. The search strategy used the following combinations of the English terms and their Spanish equivalents: "Social media," "Social networking sites," "Bodyimage," "Self-esteem," “Eating disorders," "Anorexia," "Bulimia," "Thinspo," "Self-objectification," "Instagram," "Twitter," and "Facebook". The terms were selected and combined to obtain the most results in each search.

\section{Inclusion and Exclusion Criteria}

To be included in the analysis, the studies had to meet the following criteria: 1) examine the use of an existing and widely used SM platform. To identify them, we used the results of the Pew Research Center's Internet and Technology Survey, which determines the most popular platforms (Pew Research Center, 2019); 2) include a measurement assessing and/or measuring EDs: the SCOFF questionnaire (J. F. Morgan et al., 1999), the Body Attitudes Test (Probst et al., 1995), the Bulimia Test-Revised (Thelen et al., 1991), the Eating Attitudes Test (EAT, EAT-26; Garner et al., 1982), the Body Attitudes Questionnaire (Ben-Tovim, \& Walker, 1991), the Eating Disorder Inventory (EDI, EDI-2, EDI-3; Garner, 2004), or the Eating Disorders Examination Questionnaire (EDE-Q; Fairburn et al., 1993). Validated scales and questionnaires in countries and languages other than the original were taken into account; 3) the article had to be written in English or Spanish, due to their prevalence in our search results, as they reported a large number of results, as well as the European languages comprising the largest number of speakers globally. At the same time, most often for pragmatic reasons, only publications in English and the native language are included (Ferreira et al., 2011); 4) be published from 2004 onward (the year in which Facebook emerged as the first SM platform showing photographs). 
The following exclusion criteria were established: 1) presentations, dissertations, theses, books, book chapters, communications at conferences, and other technical documents; 2) mainly qualitative studies; 3) studies about contact and dating websites, chats, and forums, online game pages, and virtual reality apps; 4) articles aimed at evaluating and examining SM groups that promote anorexia and bulimia; 5) articles on specific populations ( e.g., athletes, dancers, models, and others), which could lead to bias in the data analyses; 6 ) validations of standardized tests and instruments.

\section{Selection of Studies}

In compliance with the PRISMA guidelines, a flowchart was used to provide a general overview of the selection process for the articles (Moher et al., 2009). After the search, the articles were selected, first, based on their titles, then, on their abstracts, and finally, considering the entire journal article. At the initial stage of title selection, all articles were included whose title indicated some aspect of the use of SM, body image, and ED psychopathologies. This process was similarly followed at the abstract selection stage; qualitative studies were removed at this stage. Lastly, once the abstracts were selected, the full text was read to determine the final eligibility of the studies. Articles were only rejected at this stage if they did not include an independent measure of the use of SM and an independent measure of EDs or a component of EDs, or if they did not provide the information required to calculate the effect size.

Figure 1. Flowchart of the Articles Included in the Study.

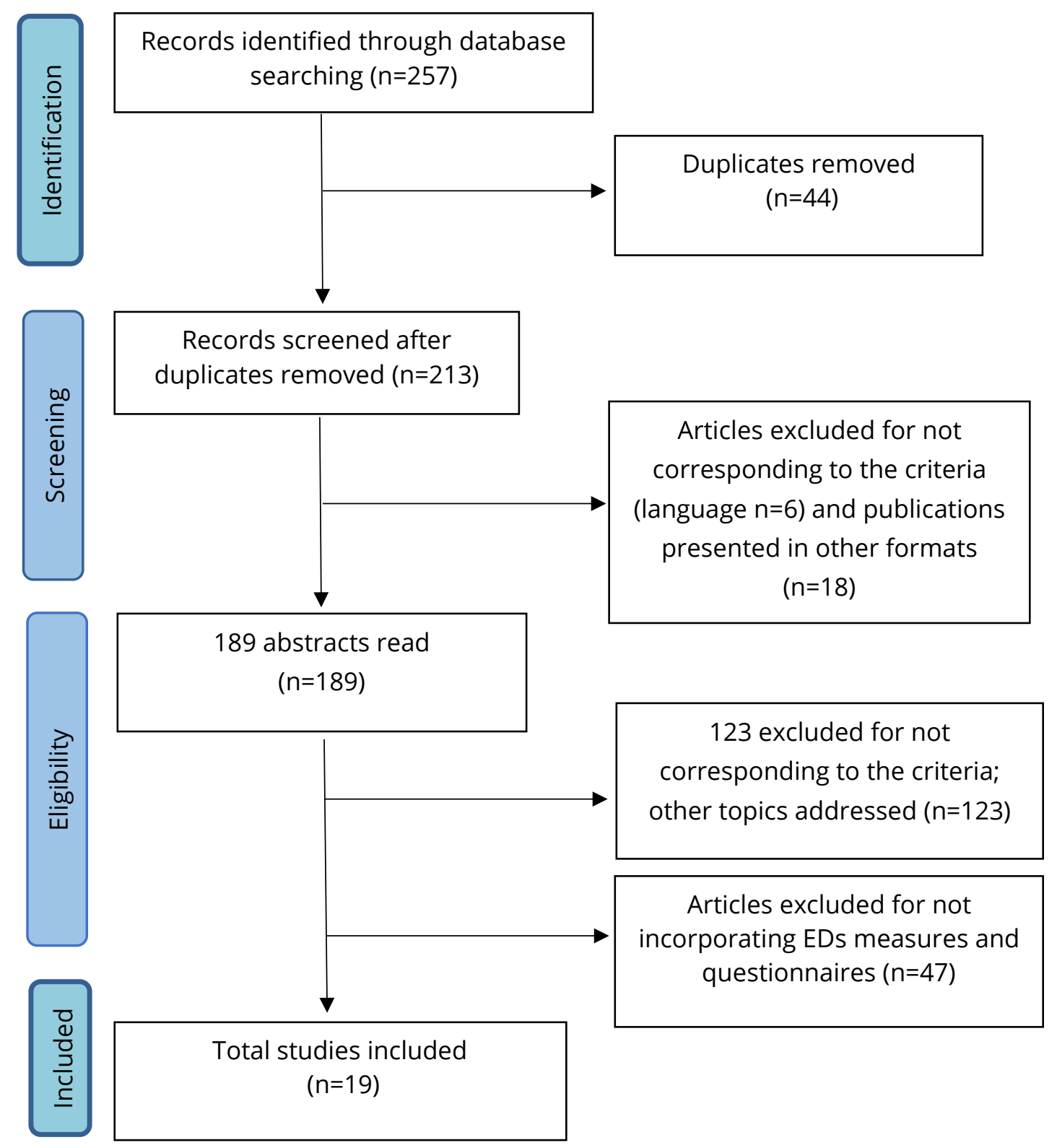


The initial selection identified a total of 257 studies, from which 44 duplicate studies were removed. After deleting 6 articles that did not meet the language criteria and 18 publications in other formats, the titles and abstracts of 189 articles were read. Of these, 123 were removed because their content did not correspond to the purpose of the study, the general use of social media and ED psychopathologies. In the final phase, 47 studies were removed for not incorporating specific ED measures, eventually resulting in a total of 19 articles that met all the previously defined criteria (Figure 1).

\section{Data Extraction}

This step was performed by two reviewers, who independently read each article and compiled the data in a template. The extraction information was made by reading the article (Moher et al., 2009) and providing the following data: author, publication year, title, editorial data, country, type of publication, category/methodology, topic, abstract, keywords, and database source. After the final selection of studies, the authorship, year, country, sample size, female percentage, design, SM measurement instruments, and key findings were also entered in the template. When questions arose about the suitability of an article in the final selection, additional information about the study was sought, and disagreements were resolved through discussion. The results of the articles analyzed were dominated by frequencies, percentages, and means.

\section{Results}

In the results phase, the 19 articles that met all the previously determined inclusion criteria were analyzed. Regarding the methodology of the studies, 17 were correlational studies (of which 3 included a longitudinal component), 1 article was descriptive, and 1 used an experimental design. Almost half of the studies included participants from the United States $(n=8)$. The remaining studies were carried out in Australia $(n=3)$, Canada $(n=2)$, Korea $(n=1)$, Thailand $(n=1)$, England $(n=1)$, Singapore $(n=1)$, The Netherlands $(n=1)$, and Fiji $(n=1)$.

Of the articles analyzed, $68.4 \%$ used only female samples $(n=13)$. Although 6 studies included male samples, in all of them, males were the minority gender. The number of participants in the selected studies increased from 55 participants in the smallest sample to 1,087 people in the largest sample. The age range of participants across the studies was between 10 and 64 years of age. The identified studies were published between 2011 and 2019. The largest number of publications took place in $2017(n=6)$, followed by $2015(n=3)$. For more information see Table 1.

Table 1. Overview of the Articles Included in the Review.

\begin{tabular}{|c|c|c|c|c|c|c|c|}
\hline $\begin{array}{l}\text { Authors } \\
\text { (Year) }\end{array}$ & Country & Design & Sample & $\begin{array}{c}\% \\
\text { Female }\end{array}$ & $\begin{array}{c}\text { SM } \\
\text { measure }\end{array}$ & $\begin{array}{l}\text { Eating } \\
\text { Disorder } \\
\text { measure }\end{array}$ & Key findings \\
\hline $\begin{array}{l}\text { Becker et al. } \\
\text { (2011) }\end{array}$ & Fiji & $\mathrm{C}$ & $\begin{array}{l}\text { Adolescents } \\
(523)\end{array}$ & 100 & $\begin{array}{l}\text { Influence of } \\
\text { and } \\
\text { exposure to } \\
\text { SM. } \\
\text { Analysis of } \\
\text { SM. }\end{array}$ & $\begin{array}{l}\text { EDs. } \\
\text { Exposures to } \\
\text { SM and EDs. }\end{array}$ & $\begin{array}{l}\text { Direct and indirect exposure to } \\
\text { SM was associated with EDs in } \\
\text { unadjusted analyses. In } \\
\text { adjusted analyses, only SM } \\
\text { exposure was associated with } \\
\text { EDs. }\end{array}$ \\
\hline $\begin{array}{l}\text { Butkowski } \\
\text { et al. } \\
(2019)\end{array}$ & USA & C & $\begin{array}{l}\text { Young adults } \\
\text { (18-30 years) } \\
(177)\end{array}$ & 100 & $\begin{array}{l}\text { Selfie } \\
\text { Feedback. }\end{array}$ & $\begin{array}{l}\text { Body } \\
\text { dissatisfaction. } \\
\text { Drive for } \\
\text { thinness. } \\
\text { Bulimia. } \\
\text { Body } \\
\text { monitoring. }\end{array}$ & $\begin{array}{l}\text { Selfie-feedback received } \\
\text { through external opinions or } \\
\text { assessments increased the } \\
\text { likelihood of body } \\
\text { dissatisfaction and the drive for } \\
\text { thinness through indirect } \\
\text { influence. This effect did not } \\
\text { extend to bulimic tendencies. }\end{array}$ \\
\hline $\begin{array}{l}\text { Cohen et al. } \\
(2017)\end{array}$ & Australia & C & $\begin{array}{l}\text { Young adult } \\
\text { (18-29 years) } \\
(259)\end{array}$ & 100 & $\begin{array}{l}\text { Use of SM. } \\
\text { Selfie } \\
\text { Activities. }\end{array}$ & $\begin{array}{l}\text { Internalization } \\
\text { of the thin ideal. } \\
\text { Body } \\
\text { Satisfaction. } \\
\text { Self- } \\
\text { objectification. } \\
\text { EDs }\end{array}$ & $\begin{array}{l}\text { Greater participation in } \\
\text { photographic activities on } \\
\text { Facebook was associated with } \\
\text { greater internalization and } \\
\text { monitoring of the body ideal. In } \\
\text { contrast, Facebook's general } \\
\text { use was not associated with } \\
\text { body monitoring. }\end{array}$ \\
\hline
\end{tabular}




\begin{tabular}{|c|c|c|c|c|c|c|}
\hline $\begin{array}{l}\text { Ferguson et } \\
\text { al. } \\
(2014)\end{array}$ & USA & $\begin{array}{l}\mathrm{C} \\
\mathrm{L}\end{array}$ & $\begin{array}{l}\text { Adolescents } \\
(237)\end{array}$ & 100 & Use of SM. & ED symptoms. \\
\hline
\end{tabular}

Peer-comparison, rather than with the media, was more relevant to body image and EDs. The use of SM predicted peer competition 6 months later, suggesting possible indirect effects for SM.

\begin{tabular}{|c|c|c|c|c|c|c|}
\hline $\begin{array}{l}\text { Hendrickse } \\
\text { et al. } \\
(2017)\end{array}$ & USA & C & $\begin{array}{l}\text { College } \\
\text { students } \\
(185)\end{array}$ & 100 & $\begin{array}{l}\text { Appearance- } \\
\text { related } \\
\text { comparisons } \\
\text { on } \\
\text { Instagram. }\end{array}$ & $\begin{array}{l}\text { Intrasexual } \\
\text { competitiveness } \\
\text { between } \\
\text { classmates. } \\
\text { Drive for } \\
\text { thinness. } \\
\text { Body } \\
\text { dissatisfaction. }\end{array}$ \\
\hline $\begin{array}{l}\text { Howard et } \\
\text { al. (2017) }\end{array}$ & USA & C & $\begin{array}{l}\text { College } \\
\text { students (892) }\end{array}$ & 100 & $\begin{array}{l}\text { Safety- } \\
\text { seeking in } \\
\text { SM. } \\
\text { Frequency } \\
\text { of use of } \\
\text { SM. }\end{array}$ & $\begin{array}{l}\text { Body image. } \\
\text { EDs }\end{array}$ \\
\hline
\end{tabular}

Using Instagram can be potentially harmful to people who often compare themselves to others. A positive relationship between intrasexual competitiveness and physical comparisons on Instagram was found.

Black women reported less body dissatisfaction, fewer possible EDs, and less use of Facebook than White women. The increased use of Facebook was associated with more body dissatisfaction (not with EDs). A greater search for selfconfidence through SM predicted more body dissatisfaction and EDs.

\begin{tabular}{|c|c|c|c|c|c|c|}
\hline $\begin{array}{l}\text { Hummel \& } \\
\text { Smith } \\
(2015)\end{array}$ & USA & $\begin{array}{l}\text { C } \\
\text { L }\end{array}$ & $\begin{array}{l}\text { University } \\
\text { students } \\
(185)\end{array}$ & 78 & $\begin{array}{l}\text { Comments } \\
\text { on } \\
\text { Facebook. } \\
\text { Status } \\
\text { updates. }\end{array}$ & EDs \\
\hline $\begin{array}{l}\text { Jin } \\
(2018)\end{array}$ & Korea & $E$ & $\begin{array}{l}\text { Women } M_{\text {age }}= \\
33.30 \text { years } \\
(141)\end{array}$ & 100 & $\begin{array}{l}\text { Feelings of } \\
\text { envy on SM. } \\
\text { Parasocial } \\
\text { interaction. } \\
\text { Friendship } \\
\text { on } \\
\text { Instagram. }\end{array}$ & $\begin{array}{l}\text { Self-esteem. } \\
\text { Perfectionism. } \\
\text { Scale of } \\
\text { anorexia / } \\
\text { bulimia. } \\
\text { Images of } \\
\text { "foodporn"." } \\
\text { Body Mass } \\
\text { Index (BMI). }\end{array}$ \\
\hline
\end{tabular}

Seeking and receiving negative comments through SM increased the risk of ED-related attitudes.

Body shape (fat/thin) and popularity (popular/unpopular) of a diner referent on Instagram affects the intention to eat compared to one's peers, as well as moderating effects on users' self-esteem, BMI, perfectionism, anorexia, and bulimia nervosa.

Envy was a mediating variable. Envy also mediated the effects of body shape and popularity of a foodie Instragramer on the parasocial interaction of peer users with the foodie and the intention to establish an Instagram-based friendship.

Kaewpradub Thailand et al.

(2017)

Meier \& USA
Gray
(2014)

Murray et Canada

al.
C

High school students (620)

C Secondary and
Preparatory
School Students (103)
60.3

$\begin{array}{ll}\text { Behavior } & \text { Body image. } \\ \text { and use of } & \text { Drive for } \\ \text { media and } & \text { Muscularity } \\ \text { the Internet. } & \text { Scale } \\ & \text { Self-esteem. }\end{array}$

100

\section{C}

Undergraduate students (383)
EDs

Obesity

behaviors.

Internet and Internalization Facebook

use.

Image exposure on Facebook.

The time spent on SM related to self-image and eating attitudes and behaviors was associated with decreased body image satisfaction and problematic eating behaviors.

High image exposure, but not of the thin ideal. Facebook's general use, Appearance comparison. correlated with dissatisfaction with weight, drive for thinness, internalizing the thin ideal, and self-objectification. with weight. Drive for thinness.

Selfobjectification.

Excessive ED-linked time on SM behavior.

Lower self-esteem was related to excessive time on SM and restricted eating for men and 


Santarossa Canada
\& Woodruff
(2017)

Saunders \& USA
Eaton

(2018)

$\begin{array}{ll}\text { Slater \& } & \text { United } \\ \text { Tiggemann } & \text { Kingdom } \\ \text { (2015) } & \end{array}$
(2015)

Tan et al. Singapore (2016)

$\begin{array}{ll}\text { D } & \text { People } \\ \text { diagnosed with } \\ \text { ED }\end{array}$

\begin{tabular}{|c|c|c|c|}
\hline $\begin{array}{l}\text { Tiggemann } \\
\text { \& Slater } \\
\text { (2014) }\end{array}$ & Australia & C & $\begin{array}{l}\text { Girls aged } 10- \\
12 \text { years } \\
\text { (189) }\end{array}$ \\
\hline
\end{tabular}

\begin{tabular}{|c|c|c|c|}
\hline $\begin{array}{l}\text { Tiggemann } \\
\text { \& Slater } \\
\text { (2017) }\end{array}$ & Australia & $\begin{array}{l}\mathrm{C} \\
\mathrm{L}\end{array}$ & $\begin{array}{l}\text { High school } \\
\text { students } \\
\text { (438) }\end{array}$ \\
\hline
\end{tabular}

Walker et al. USA (2015)

$\begin{array}{ll}\text { Yellowlees } & \text { The } \\ \text { et al. (2019) } & \text { Netherlands }\end{array}$

C

C

Undergraduate 55
students
(147)

Young adults (18-24yearsold)

Adolescents
$(1.087)$

100

100

and use of

SM

time/day.

Friends on

Body image.

SM.

Activities on

SM.

and use of monitoring.

SM.

\section{Social}

comparison.

Body

EDs.

Exposure to Comments on

Facebook appearance.

and Self-

MySpace

media and

94.5

SM and

mobile

applications.

objectification.

Self-monitoring.

Body shame.

EDs

EDs on the

Internet.

Characteristics

of the disorder.

97.5

Exposure to

Facebook

and

Myspace

media and

networks.

100

Use of

Facebook.

C

\section{College}

students

(128)

C dissatisfaction.
Women $\left(M_{\text {age }}=100\right.$ 22.44 years)

(152)
Body image:

appearance and

weight.

networks.

women. The relationship

between excessive time on SM

and emotional eating, or moodrelated eating was greater in women.

The study demonstrated the influence of excessive use of SM on symptoms and body image concerns, self-esteem, and EDs.

There is a link between comparisons and EDs, and between body monitoring and disordered eating. Empirical findings support the extension of the sociocultural model of EDs to include the uses and gratifications of SM.

Exposure to magazines and SM was associated with selfobjectification. Positive comments related to appearance influenced selfobjectification as much as negative comments.

The use of mobile applications was associated with greater severity of the disease. $41.8 \%$ of people with EDs felt that the applications helped perpetuate their illness, whereas $32.7 \%$ felt that the applications were useful for recovery.

The time spent on SM was linked to the internalization of the thin ideal, body monitoring, and drive for thinness. Facebook users scored higher in measures of body image concerns.

Increased participation of Internet users on Facebook over the two years of research was found. Body monitoring prospectively predicted the increase in the number of friends on Facebook. Increased intensity in Facebook usage was associated with decreased ED-linked behavior, whereas both the comparison of physical appearance on SM and online weight-loss chats and conversations were associated with EDs.

Use of SM. ED and severity. No direct link was found Selfie BMI between body dissatisfaction behavior. Body dissatisfaction. Body control. Body avoidance. Self-esteem. and selfie photographs in general. A relationship was found between selfies not posted on SM whose intention was body review: the greater the number of unposted selfies, the greater the severity of the ED symptoms.

\footnotetext{
Note. C: Correlational; L: Longitudinal; E: Experimental; D: Descriptive.
} 
From the organization and analysis of the main findings of each of the articles, 5 categories were identified that synthesize the results on the use of SM and ED psychopathologies. The 5 categories identified correspond to: Time spent on SM; Use of and interaction through SM; Sociocultural influence; Gender influence; Self-esteem and satisfaction with body image.

\section{Time Spent on SM}

The time spent on SM and the development of ED psychopathologies were strongly related in studies that considered both variables. Authors like Kaewpradub and colleagues (2017) found that the time spent on imagerelated SM was associated with problematic eating behaviors. Reinforcing this idea, Santarossa and Woodruff (2017) reported that over-use of SM is related to body image concerns, self-esteem, and ED psychopathologies. Tiggemann and Slater (2014) agreed on the relationship between usage time and the internalization of the thin ideal, body monitoring, and drive for thinness. The study by Murray et al. (2016) revealed that lower weight and appearance esteem mediated the relationship between excessive time on SM and restrained eating for males and females. One study indicated that the increased use of Facebook was associated with more body dissatisfaction but not directly with EDs (Howard et al., 2017).

Regarding the daily connection time, Santarossa and Woodruff (2017) found that female participants connected to SM between 3.9 to 4.1 hours daily, and their male counterparts between 2.8 and 2.9 hours. Yellowlees et al. (2019) reported that $98 \%$ of the participants used SM accounts, with an average daily usage of 2.52 hours (SD = 2.34), highlighting the time spent on Facebook, followed by Instagram. The result with a lower daily average on SM (MySpace and Facebook) was 81.31 minutes $(S D=99.20)$ (Slater \& Tiggemann, 2015).

Tiggemann's and Slater's (2017) study included a longitudinal component and found that the number of Facebook profiles increased over a two-year period from 71.7 to $91.3 \%$, as did the connection time, the average number of contacts, and concern for body image. Concerning the drive for thinness, these authors observed that, after its initial measurement $(M=17.65, S D=9.32)$, it increased at the second measurement $(M=20.51, S D=9.73)$. The time spent on SM had stronger correlations with concern for body image than did the general exposure to the Internet, representing a powerful socio-cultural influence among preadolescent girls (Tiggemann \& Slater, 2014).

\section{Use of and Interaction Through SM}

Interaction through comments, photo sharing, and selfies was very relevant for the dissatisfaction with and control of body image. In early papers that addressed the subject, such as that of Tiggemann and Slater (2014), it was observed that $14 \%$ of the girls had a MySpace profile and $43 \%$ had a Facebook profile. In subsequent studies, three out of four participants (75.1\%) reported having a Facebook profile, and $46.3 \%$ had a MySpace profile (Slater \& Tiggemann, 2015). Authors like Saunders and Eaton (2018) identified new patterns, incorporating SM into their study of Instagram and Snapchat, observing the following results: $15.1 \%$ of the participants were Facebook users, $33.6 \%$ were Snapchat users, and 51.3\% were users of Instagram, which represented the most frequently used platform.

Together with the percentage of SM usage, the type of interaction that occurred on the networks was very relevant in the works analyzed. The total number of friends and specific activities, such as looking at other people's profiles or leaving comments, were directly related to concern for body image, self-esteem, and EDs among adolescents (Santarossa \& Woodruff, 2017). The longitudinal study by Tiggemann and Slater (2017) found that body internalization and monitoring predicted an increase in the number of friends. As for presenting images of friends' bodies versus those of famous people, Hendrickse et al. (2017) emphasized the need to differentiate the effects produced, with a greater influence of known peers over celebrities. In this line of argument, Ferguson et al. (2014) found that the comparison between known peers is more relevant for body self-esteem and eating problems among adolescent girls.

Concerning self-objectification indices, in the sense of judging one's body compared to social standards, it was noted that Facebook users have higher self-objectification $(M=2.17, S D=12.85)$ than non-users of this SM $(M=$ $5.59, S D=14.62)$. The authors also reported that people who devoted much of their time on SM to photo sharing were more likely to develop body dissatisfaction and drive for thinness (Meier \& Gray, 2014). 
The control of body mass index (BMI) associated with following health and physical exercise accounts correlated positively with the internalization of the thin ideal and drive for thinness (Cohen et al., 2017). The study conducted by Butkowski et al. (2019) found that the drive for thinness also correlated with feedback received from selfies and body monitoring. Yellowlees et al. (2019) noted that the relationship between the total number of selfies and EDs was nonsignificant, such that those who posted the most selfies did not report more body dissatisfaction. However, these authors did find that unposted selfies were linked to body dissatisfaction and monitoring.

Concerning the comments received, Hummel and Smith (2015) noted that the search for feedback through comments predicted food restriction when a large number of comments was received. Those who received many comments and those who received negative feedback through SM were more likely to report food restriction at the second period of their longitudinal study. For Slater and Tiggemann (2015), comments on the SM about physique, both positive and negative, were positively related to self-objectification and self-monitoring. Positive comments on appearance $(M=3.04, S D=1.35)$ were received more than negative ones $(M=1.08, S D=1.28)$. In sum, the corpus of scholarly literature reviewed above highlights the importance of including SM-dynamics in research studies on body concern and EDs (Slater \& Tiggemann, 2015).

The only study that focused on patients with an ED diagnosis highlighted that significant use of apps and smartphones prolonged or worsened the behavior in the most severe cases of the disease, finding that $41.8 \%$ of the diagnosed people felt that the apps helped perpetuate the disease (Tan et al., 2016).

\section{Sociocultural Influence}

Sociocultural influence has been reaffirmed through the results as one of the determinants of the possible development of ED psychopathologies. The variation and sociocultural representativeness of the different samples varied depending on the article analyzed. However, a predominance of Caucasian samples was observed, as in Walker et al. (2015), a study in which Caucasians accounted for 81.3\%; in Cohen et al. (2017) with 77.5\%; and in Butkowski et al. (2019), with 60\%. The following works were noteworthy for collecting different samples: Ferguson et al. (2014), in which most participants were Hispanic (94.1\%), a reflection of the community surrounding the university; the study examining a Western and ethnic sample in Fiji (Becker et al., 2011); and the work that used a racial perspective, where Black women accounted for $48.26 \%$ of the sample (Howard et al., 2017).

In the work with the Fijian sample (Becker et al., 2011), not only ethnic issues were considered, but also Western exposure through trips abroad. As for the research that explored the differences between Black and White women, the result suggested less body dissatisfaction and a lower likelihood of EDs in Black women, as well as more frequent use of Facebook among White women seeking greater validation (Howard et al., 2017). Focusing on the Fiji study, ethnic cultural orientation was associated with a lower incidence of EDs, whereas trips abroad were associated with a higher likelihood of EDs (Becker et al., 2011). Concerning Black women, they were observed to experience lower levels of body dissatisfaction and marginally lower levels of EDs than White women (Howard et al., 2017).

\section{Gender Influence}

Of all the studies reviewed, $68.4 \%$ examined exclusively female samples, addressing the impact of SM use on body image and EDs mostly from a female perspective. Although some investigations had male samples, not all of them developed and analyzed gender differences (Hummel \& Smith, 2015; Tiggemann \& Slater, 2014).

Authors such as Santarossa and Woodruff (2017) argued that the few existing gender differences could be attributed to the use of gender-specific tools when available, for example, the SATAQ-3 female version and the SATAQ-M male version.

On average, male participants used general media for more time but females used the Internet and SM more, as a means of body image-related content, and $61.3 \%$ of them sought body-image-related products on SM (Kaewpradub et al., 2017). In the gender analysis, female high school participants reported significant differences in purging behaviors, laxative use, weight loss pills, and excessive exercise (Kaewpradub et al., 2017). However, 
male high school participants scored significantly higher in behaviors that imply a risk of obesity (Kaewpradub et al., 2017).

Murray et al. (2016) revealed that females had a significantly more contained and emotional diet, poorer selfesteem about their appearance, and a worse perception of their weight, which mediated their overuse of SM. It was also revealed that on the SM, women engage in more social comparison activities, and men tend to use SM to make friends and expand their social network. However, research results show that men's body image and dietary behaviors are also influenced by SM (Murray et al., 2016).

In the study that analyzed a clinical sample (Tan et al., 2016), the participants were mostly women (94.5\%). In this sense, the authors state that the small male sample could limit the generalization of this study to male individuals with EDs. Consequently, they established the need for future studies to include more male participants with EDs.

\section{Self-Esteem and Satisfaction With Body Image}

This systematic review shows that, in some studies, problematic use of SM was associated with decreased selfesteem and satisfaction, alteration of body image, and a possible increase of depressive behaviors.

Excessive time on SM was associated with lower self-esteem about physique, which, in turn, was related to increased dietary restriction (Kaewpradub et al., 2017). The results of the study by Santarossa and Woodruff (2017) suggested that symptoms derived from the problematic use of SM are worrisome, as they were associated with lower self-esteem and more symptoms of EDs. Comparisons related to appearance provided through Instagram were positively associated with concern for body image, suggesting that the greater the body dissatisfaction, the higher the drive for thinness (Hendrickse et al., 2017).

Walker et al. (2015) reported that BMI and depression explained variations in the development of EDs, as well as the comparison of physical appearance on SM. Ferguson et al. (2014) observed a small correlation between the use of SM and a reduction in life satisfaction.

The study of Kaewpradub et al. (2017) found that one-third of the participants had abnormal attitudes towards eating and body image. Internet and SM usage were negatively associated with body image satisfaction but positively associated with inappropriate eating behaviors, binges, purges, laxative use, diuretics, and drive for muscularity. Similarly, Walker et al. (2015) observed that the presentation of one's image on Facebook was positively correlated with the internalization of the thin ideal, self-objectification, and drive for thinness.

\section{Discussion}

The results of this study show that the use and dynamics generated in SM can determine the appearance and/or permanence of behaviors linked to ED psychopathologies. The time spent on SM, the interactions and dynamics, the sociocultural influence, gender, and self-esteem have all been shown to influence the type of exposure, utilization of SM, and also the possible development of ED psychopathologies. Usage patterns varied depending on the year in which the study was conducted, largely due to the rapid changes that occur in the functionalities of SM (Pantic, 2014), and the age of the SM users.

The time spent on SM linked to the development of EDs is a determining factor, as it increases the exposure and visualization of beauty references with which to compare oneself. Thus, as proposed by the Social Comparison Theory (Festinger, 1954), through SM, one arrives at a self-assessment of one's abilities and skills by comparing oneself with others. At the same time, the greater the exposure to SM, the greater the possibility of internalizing the thin ideal of beauty (Tiggemann \& Slater, 2014). It is noteworthy that the most recent studies that considered the time spent on SM (Santarossa \& Woodruff, 2017; Yellowlees et al., 2019) observed more minutes of daily consumption, compared to less recent research (Slater \& Tiggemann, 2015), confirming the increasing tendency of SM consumption. This was also seen in the longitudinal study by Tiggemann and Slater (2017). In general, the increase in time spent on SM produces stronger correlations with concern for image (Tiggemann \& Slater, 2014). 
Interactions that occur in SM play a decisive role in the content that is presented and perceived, which is a predictor of concern for one's image (arising from the desire to receive feedback in comments and "likes" for published photos). Although SM has the potential to strengthen social relationships, negative reviews and comments can also occur (Hummel \& Smith, 2015). As posited in the Parasocial Interaction Theory (Horton \& Wohl, 1956), the illusion of reciprocal interaction that the audience experiences toward media figures can influence the comparison with their own body. As for the self-assessments of one's body that can be produced through SM, we highlight selfies seeking social validation oriented to physical appearance, which is reinforced through "likes" and comments by third parties (Butkowski et al., 2019). However, unposted selfies revealed greater bodily control behavior, associated with possible more severe EDs (Yellowlees et al., 2019). It is also essential to consider and attend to the type of accounts that are followed, such as health, beauty, and physical exercise accounts that correlate with the drive for thinness (Cohen et al., 2017). Another dynamic determinant of the use of SM is that it can serve as a means to anonymously seek support and recommendations through online communities that encourage thinness ("thinspo"), anorexia ("proana"), or bulimia ("promia") (Brotsky \& Giles, 2007; McCormack \& Coulson, 2009), all of which can encourage EDs to be kept off the radar of family and friends (Gavin et al., 2008). However, Tiggemann et al. (2013) note that, if body image is perceived as an unrealistic objective, adolescent girls will be less likely to compare themselves socially with such images.

Sociocultural influence is relevant to the etiology of EDs (Black \& Grant, 2014) and has been considered in a large part of the reviewed articles. Sociocultural perspectives suggest that societies have different body ideals that change over time, highlighting the tripartite influence model (van den Berg et al., 2002), which proposes that the media, peers, and family are key sociocultural channels for the transmission of these ideals. In this sense, the great growth in SM usage that is occurring should be borne in mind (Statista, 2021). Currently, Caucasians have constituted the predominant population in studies that examined the use of SM and its influence on EDs, with the exception of the following studies: Ferguson et al. (2014), an investigation in which Hispanic participants predominated; the study that used ethnic samples from Fiji (Becker et al., 2011); and the work that analyzed Black and White populations (Howard et al., 2017). The study that used the Fijian sample also considered an external sociocultural influence, expressly considering personal trips abroad, which was associated with more EDs (Becker et al., 2011). These results might be explained through the trend toward the globalization of body image, and the thin ideal of Western beauty that is fostered through the media (Yan \& Bissell, 2014). The study with a Hispanic sample is of particular interest, given the lack of scholarly works on Hispanic populations (Ferguson et al., 2014). The diverse results obtained across these studies highlight the need for future studies to delve into sociodemographic issues, focusing on more diverse samples and also addressing socioeconomic differences.

The data in this systematic review showed the predominance of articles that have only studied female samples. In the six articles that did include males and females, analyses were limited to the female population and showed girls' increased likelihood of weight dissatisfaction, dieting to control weight, and purging (Anderson \& Bulik, 2004; Lewinsohn et al., 2002). This trend is consistent with reports by the American Academy of Pediatrics (2003), which state that males constitute only $10 \%$ of all ED cases. Although the multifactorial perspective of the etiopathogenesis of body image suggests that gender creates a disadvantage and increases the women's risk of EDs (Worell \& Todd, 1996), further research comparing the two genders is needed. Related to gender, we have also seen issues such as intrasexual competitiveness, proposed by Hendrickse et al. (2017), which has a positive relationship with comparisons that occur on Instagram. Of the works that also studied males, 26.3\% observed significant differences such as girls' increased dissatisfaction with weight and weight management behaviors, which is reinforced by the increased prevalence of EDs among women (Keski-Rahkonen \& Mustelin, 2016). The World Health Organization (WHO, 2019) indicates that these alterations usually occur during adolescence and early adulthood and are more common among women, which is compounded by girls' increased use of the Internet and SM with body-image-related content (Kaewpradub et al., 2017). However, more research is needed to build on the initial findings of Murray et al. (2016), which indicated that men's body image is also influenced by SM, and thereby clarify how the use of SM impacts body image and EDs among boys. There is some research in this area, such as that of Griffiths et al. (2018), who looked into adaptive and maladaptive SM usage in the context of body dissatisfaction, EDs, and anabolic steroid use. More work is needed, however, to further address the sociocultural influence in the male population (Griffiths et al., 2018).

Most young people want to be accepted by their peers, so they attach more importance to their physical appearance as a way to gain approval by others, comparing themselves to others on SM, which, in turn, relates to lower self-esteem the more time they spend on SM (Kaewpradub et al., 2017). In addition to a concern for image 
and self-esteem, the study of Santarossa and Woodruff (2017) also reported a higher probability of ED and associated ED symptoms. Black women tended to have significantly higher levels of self-esteem and were less likely to compare their body to that of others (Quick \& Byrd-Bredbenner, 2014). These behavior patterns can be better understood from the Objectification Theory (Frederickson \& Roberts, 1997), which posits that women's bodies have been constructed socially as objects to be observed. As a consequence, women may practice selfmonitoring, judging, and self-observing according to social standards, as if they were an external viewer.

Health workers and relatives of people with ED psychopathologies are largely unaware of the relationship between SM and this group of pathologies. It is hoped that this systematic review will help draw attention to the effects that continued use of SM can have on EDs. Sowles et al. (2018) reported that more than half of the parents of ED patients in their sample did not know the dynamics and interaction processes that occur in SM. The patterns of the drive for thinness (Tiggemann \& Slater, 2017), internalization of the thin ideal through SM (Meier \& Gray, 2014), and inappropriate eating behavior (Walker et al., 2015) can encourage, worsen, and normalize illness behaviors through continued use of SM (Tan et al., 2016). Specialists should also be attentive to body monitoring and validation behaviors through selfies among people with EDs, as these issues should be considered possible indicators of the development of pathology (Yellowlees et al., 2019).

A study on general Internet use and body image has concluded that public health efforts are needed to support girls and young women to achieve and maintain a positive body image in the current digital age (Carter et al., 2017). It is necessary to provide guidelines for healthy Internet use, as well as to reinforce girls' and women's authentic identity (not what is projected on SM) (Carter et al., 2017). To our knowledge, to date, there is only one other published review article linking SM usage and body image (Fallon et al., 2014) although that study did not include in its evaluation criteria that the studies reviewed must have ED measures. In this sense, the present review fills an important gap in the literature on ED psychopathologies.

The interactive nature of SM requires concrete and up-to-date research. SM are also a predominant media during the age of onset of the development of ED psychopathologies-puberty and adolescence. This systematic review may serve to gather key findings on the subject, helping to identify potential limitations and continue to address this topic through organized knowledge on the subject. Thus, the results can also be integrated into future research and discussions on the development of ED psychopathologies and the influence of SM. Moreover, this systematic review aims to respond to professional demands for comprehension of the use of SM and the development of ED psychopathologies, as well as to serve as the basis for generating preventive interventions when necessary (Šmahelová et al., 2019).

The PECO method (R. L. Morgan et al., 2018) was utilized to obtain greater accuracy in the selection of studies for inclusion in this systematic review as well as for establishing internal validity. The authors carried out an evaluation and examination of the quality and relevance of individual articles, using validated templates (Briggs, 2020). The discussion of the articles to achieve consensus strengthened the reliability. Each reviewer individually synthesized the results, followed by a joint discussion and assessment of each study, and finishing with the assignment of the studies to the categories presented in this systematic review. The number of articles in this synthesis of the existing literature further adds to the contribution to the field.

As a limitation of this study, it should be noted that there is only one clinical sample; a greater number of clinical samples could help to further define coping strategies. The databases (Web of Science, Scopus, PubMed, and PsycINFO) were chosen for their predominance in multiple fields although, certainly, a larger number of databases might have yielded additional results. Another limitation lies in the impossibility of computing the average age of the participants in each of the studies (due to variability in how the findings were reported). Had this comparison been possible, we would have been able to compare the studies with even more granularity. Although the inclusion of video-predominant media went beyond the scope of the present study, future studies could also benefit from comparing video versus picture exposure. Future reviews that include studies published in additional languages would also positively contribute to research in this area. 


\section{Conclusion}

This systematic review provides a synthesis of the current state of knowledge on the relationship between the use of SM and ED psychopathologies and notes that the use of SM is significantly linked to body image concerns and the possible development and/or perpetuation of EDs.

After analyzing the studies, a predominance of studies published in international journals mainly from the United States $(n=8)$ was identified. Thus, given the corroborated sociocultural influence, we underscore the need to increase research in territories such as southern Europe, where no research was found in this area despite the high use of SM. Thus, is necessary to expand the sociocultural diversity of the samples, as well as to work with a larger male sample. A greater number of longitudinal studies would help to determine and clarify how SM influences the development or permanence of EDs over time. Similarly, it would be relevant to have a greater number of experimental and quasi-experimental studies to better establish cause-and-effect relationships between variables and more robust conclusions on the impact of the use of SM on body image and ED psychopathologies. As this review has shown, interest and concern about the effect of SM usage on body image and ED psychopathologies are growing. However, studies that directly address socialization on the SM and EDs must also attend to the rapid changes and dynamics occurring in SM platforms as elements of communication and relationship in contemporary society. Prevention related to these media also needs to be promoted, to generate skills and information to resist media messages issued concerning the Western ideal of bodily perfection.

\section{Footnotes}

1. "Foodporn" refers to the eye-catching exposure of food through SM.

\section{Acknowledgement}

This research was funded by the Ourense Provincial Council and the University of Vigo (DIXITOU1-X002).

\section{References}

American Academy of Pediatrics. (2003). Identifying and treating eating disorders. Pediatrics, 111(1), 204-211. https://doi.org/10.1542/peds.111.1.204

American Academy of Pediatrics. (2016). Media and young minds. Pediatrics, 138(5), Article e20162591. https://doi.org/10.1542/peds.2016-2591

American Psychiatric Association. (2013). Diagnostic and statistical manual of mental disorders: DSM-5 ${ }^{\mathrm{TM}}$ (5th ed.). American Psychiatric Publishing, Inc. http://dx.doi.org/10.1176/appi.books.9780890425596

Anderson, C. B., \& Bulik, C. M. (2004). Gender differences in compensatory behaviors, weight and shape salience, and drive for thinness. Eating Behaviors, 5(1), 1-11. http://dx.doi.org/10.1016/j.eatbeh.2003.07.001

Becker, A. E., Fay, K. E., Agnew-Blais, J., Khan, A. N., Striegel-Moore, R. H., \& Gilman, S. E. (2011). Social network media exposure and adolescent eating pathology in Fiji. The British Journal of Psychiatry, 198(1), 43-50.

http://dx.doi.org/10.1192/bjp.bp.110.078675

Ben-Tovim, D. I., \& Walker, M. K. (1991). The development of the Ben-Tovim Walker Body Attitudes Questionnaire (BAQ), a new measure of women's attitudes towards their own bodies. Psychological Medicine, 21(3), 775-784. http://dx.doi.org/10.1017/S0033291700022406

Black, D. W., \& Grant, J. E. (2014). DSM-5® guidebook: The essential companion to the diagnostic and statistical manual of mental disorders. American Psychiatric Publishing, Inc.

Blood, S. K. (2005). Body work: The social construction of women's body image. Routledge. 
Brichacek, A., Neill, J., \& Murray, K. (2018). The effect of basic psychological needs and exposure to idealised Facebook images on university students' body satisfaction. Cyberpsychology: Journal of Psychosocial Research on Cyberspace, 12(3), Article 2. https://doi.org/10.5817/CP2018-3-2

Briggs, J. (2020) JBI's critical appraisal tools assist in assessing the trustworthiness, relevance and results of published papers. Retrieved March 3, 2020, from https://joannabriggs.org/critical-appraisal-tools

Brotsky, S. R., \& Giles, D. (2007). Inside the "pro-ana" community: A covert online participant observation. Eating Disorders, 15(2), 93-109. http://dx.doi.org/10.1080/10640260701190600

Butkowski, C. P., Dixon, T. L., \& Weeks, K. (2019). Body surveillance on Instagram: Examining the role of selfie feedback investment in young adult women's body image concerns. Sex Roles, 81(5-6), 385-397.

http://dx.doi.org/10.1007/s11199-018-0993-6

Carter A., Forrest J. I., Kaida A. (2017). Association between Internet use and body dissatisfaction among young females: Cross-sectional analysis of the Canadian Community Health Survey. Journal of Medical Internet Research, 19(2), Article e39. http://dx.doi.org/10.2196/jmir.5636

Chesney, E., Goodwin, G. M., \& Fazel, S. (2014). Risks of all-cause and suicide mortality in mental disorders: A meta-review. World Psychiatry, 13(2), 153-160. http://dx.doi.org/10.1002/wps.20128

Clark, J. L., Algoe, S. B., \& Green, M. C. (2018). Social network sites and well-being: The role of social connection. Current Directions in Psychological Science, 27(1), 32-37. http://dx.doi.org/10.1177/0963721417730833

Cohen, R., Newton-John, T., \& Slater, A. (2017). The relationship between Facebook and Instagram appearancefocused activities and body image concerns in young women. Body Image, 23, 183-187.

http://dx.doi.org/10.1016/j.bodyim.2017.10.002

Eurostat. (2020). Individuals using the Internet for participating in social networks. Retrieved May 20, 2020, from https://appsso.eurostat.ec.europa.eu/nui/show.do?dataset=isoc_ci_ac_i\&lang=en

Fairburn, C. G. \& Cooper, Z. (1993). The eating disorder examination. In C. G. Fairburn, \& G. T. Wilson G. (Eds.), C.G. Binge eating: Nature, assessment, and treatment (pp. 317-360). Guilford Press.

Fairburn, C. G., Cooper, Z., \& O'Connor, M. (1993). The eating disorder examination. International Journal of Eating Disorders, 6, 1-8.

Fallon, E. A., Harris, B. S., \& Johnson, P. (2014). Prevalence of body dissatisfaction among a United States adult sample. Eating Behaviors, 15(1), 151-158. http://dx.doi.org/10.1016/j.eatbeh.2013.11.007

Fardouly, J., Pinkus, R. T., \& Vartanian, L. R. (2017). The impact of appearance comparisons made through social media, traditional media, and in person in women's everyday lives. Body Image, 20, 31-39.

https://doi.org/10.1016/j.bodyim.2016.11.002

Ferguson, C. J., Muñoz, M. E., Garza, A., \& Galindo, M. (2014). Concurrent and prospective analyses of peer, television and social media influences on body dissatisfaction, eating disorder symptoms and life satisfaction in adolescent girls. Journal of Youth and Adolescence, 43(1), 1-14. http://dx.doi.org/10.1007/s10964-012-9898-9

Ferreira González, I., Urrútia, G., \& Alonso-Coello, P. (2011). Systematic reviews and meta-analysis: Scientific rationale and interpretation. Revista Española de Cardiología, 64(8), 688-696.

http://dx.doi.org/10.1016/j.rec.2011.03.027

Festinger, L. (1954). A theory of social comparison processes. Human Relations, 7(2), 117-140.

http://dx.doi.org/10.1177/001872675400700202 
Frederick, D. A., Daniels, E. A., Bates, M. E., \& Tylka, T. L. (2017). Exposure to thin-ideal media affect most, but not all, women: Results from the Perceived Effects of Media Exposure Scale and open-ended responses. Body Image, 23, 188-205. http://dx.doi.org/10.1016/j.bodyim.2017.10.006

Frederickson, B. L., \& Roberts, T.-A. (1997). Objectification theory: Toward understanding women's lived experiences and mental health risks. Psychology of Women Quarterly, 21(2), 173-206.

http://dx.doi.org/10.1111/j.1471-6402.1997.tb00108.x

Garner, D. M. (2004). Eating Disorder Inventory-3 (EDI-3): Professional manual. Psychological Assessment Resources.

Garner, D. M., Olmsted, M. P., Bohr, Y. \& Garfinkel, P. E. (1982). The eating attitudes test: Psychometric features and clinical correlates. Psychological Medicine, 12(4), 871-878. http://dx.doi.org/10.1017/S0033291700049163

Gavin, J., Rodham, K., \& Poyer, H. (2008). The presentation of "pro-anorexia" in online group interactions. Qualitative Health Research, 18(3), 325-333. https://doi.org/10.1177/1049732307311640

Goldstein, A., \& Gvion, Y. (2019). Socio-demographic and psychological risk factors for suicidal behavior among individuals with anorexia and bulimia nervosa: A systematic review. Journal of Affective Disorders, 245, 1149-1167. http://dx.doi.org/10.1016/j.jad.2018.12.015

Grabe, S., Ward, L. M., \& Hyde, J. S. (2008). The role of the media in body image concerns among women: A metaanalysis of experimental and correlational studies. Psychological Bulletin, 134(3), 460-476.

https://doi.org/10.1037/0033-2909.134.3.460

Griffiths, S., Murray S. B., Krug I., \& McLean S. A. (2018). The contribution of social media to body dissatisfaction, eating disorder symptoms, and anabolic steroid use among sexual minority men. Cyberpsychology, Behavior, and Social Networking, 21(3), 149-156. http://dx.doi.org/10.1089/cyber.2017.0375

Grogan, S. (2016). Body image: Understanding body dissatisfaction in men, women and children. Routledge.

Gruzd, A., Jacobson, J., Mai, P., \& Dubois, E. (2018). The state of social media in Canada 2017 (Version 1.0). Ryerson University Social Media Lab. http://dx.doi.org/10.5683/SP/AL8Z6R

Gündüz, U. (2017). The effect of social media on identity construction. Mediterranean Journal of Social Sciences, 8(5), 85-85. http://dx.doi.org/10.1515/mjss-2017-0026

Hendrickse, J., Arpan, L. M., Clayton, R. B., \& Ridgway, J. L. (2017). Instagram and college women's body image: Investigating the roles of appearance-related comparisons and intrasexual competition. Computers in Human Behavior, 74, 92-100. http://dx.doi.org/10.1016/j.chb.2017.04.027

Hilbert, A., Pike, K. M., Goldschmidt, A. B., Wilfley, D. E., Fairburn, C. G., Dohm, F.-A., Walsh, B. T. \& Weissman, R. S. (2014). Risk factors across the eating disorders. Psychiatry Research, 220(1-2), 500-506.

https://doi.org/10.1016/j.psychres.2014.05.054

Hogue, J. V., \& Mills, J. S. (2019). The effects of active social media engagement with peers on body image in young women. Body Image, 28, 1-5. http://dx.doi.org/10.1016/j.bodyim.2018.11.002

Holland, G., \& Tiggemann, M. (2016). A systematic review of the impact of the use of social networking sites on body image and disordered eating outcomes. Body Image, 17, 100-110.

http://dx.doi.org/10.1016/j.bodyim.2016.02.008

Horton, D. \& Wohl, R. R. (1956). Mass communication and para-social interaction: Observations on intimacy at a distance. Psychiatry, 19(3), 215-229. http://dx.doi.org/10.1080/00332747.1956.11023049 
Hou, Y., Xiong, D., Jiang, T., Song, L., \& Wang, Q. (2019). Social media addiction: Its impact, mediation, and intervention. Cyberpsychology: Journal of Psychosocial Research on Cyberspace, 13(1), Article 4 http://dx.doi.org/10.5817/CP2019-1-4

Howard, L. M., Heron, K. E., MacIntyre, R. I., Myers, T. A., \& Everhart, R. S. (2017). Is use of social networking sites associated with young women's body dissatisfaction and disordered eating? A look at Black-White racial differences. Body Image, 23, 109-113. http://dx.doi.org/10.1016/j.bodyim.2017.08.008

Hummel, A. C., \& Smith, A. R. (2015). Ask and you shall receive: Desire and receipt of feedback via Facebook predicts disordered eating concerns. International Journal of Eating Disorders, 48(4), 436-442.

http://dx.doi.org/10.1002/eat.22336

Jin, S. V. (2018). Interactive effects of Instagram foodies' hashtagged \#foodporn and peer users' eating disorder on eating intention, envy, parasocial interaction, and online friendship. Cyberpsychology, Behavior, and Social Networking, 21(3), 157-167. http://dx.doi.org/10.1089/cyber.2017.0476

Kaewpradub, N., Kiatrungrit, K., Hongsanguansri, S., \& Pavasuthipaisit, C. (2017). Association among Internet usage, body image and eating behaviors of secondary school students. Shanghai Archives of Psychiatry, 29(4), 208-217. http://dx.doi.org/10.11919/j.issn.1002-0829.216092

Keski-Rahkonen, A., \& Mustelin, L. (2016). Epidemiology of eating disorders in Europe: Prevalence, incidence, comorbidity, course, consequences, and risk factors. Current Opinion in Psychiatry, 29(6), 340-345.

http://dx.doi.org/10.1097/YCO.0000000000000278

Kim, M. (2020). Instagram selfie-posting and young women's body dissatisfaction: Investigating the role of selfesteem and need for popularity. Cyberpsychology: Journal of Psychosocial Research on Cyberspace, 14(4), Article 4. https://doi.org/10.5817/CP2020-4-4

Kwon, M. (2020) Media influences on body image \& eating behaviors in adolescents. In Y. N. Evans \& A. Dixon Docter (Eds.), Adolescent nutrition (pp. 177-235). Springer. https://doi.org/10.1007/978-3-030-45103-5_7

Lewinsohn, P. M., Seeley, J. R., Moerk, K. C., \& Striegel-Moore, R. H. (2002). Gender differences in eating disorder symptoms in young adults. International Journal of Eating Disorders, 32(4), 426-440.

http://dx.doi.org/10.1002/eat.10103

Ljungberg, T., Bondza, E., \& Lethin, C. (2020). Evidence of the importance of dietary habits regarding depressive symptoms and depression. International Journal of Environmental Research and Public Health, 17(5), Article 1616. http://dx.doi.org/10.3390/ijerph17051616

Loth, K. A., MacLehose, R., Bucchianeri, M., Crow, S., \& Neumark-Sztainer, D. (2014). Predictors of dieting and disordered eating behaviors from adolescence to young adulthood. Journal of Adolescent Health, 55(5), 705-712. https://doi.org/10.1016/j.jadohealth.2014.04.016

Mabe, A. G., Forney, K. J., \& Keel, P. K. (2014). Do you "like" my photo? Facebook use maintains eating disorder risk. International Journal of Eating Disorders, 47(5), 516-523. http://dx.doi.org/10.1002/eat.22254

McCormack, A., \& Coulson, N. S. (2009). Individuals with eating disorders and the use of online support groups as a form of social support. Cyberpsychology: Journal of Psychosocial Research on Cyberspace, 3(2), Article 5. https://cyberpsychology.eu/article/view/4228/3271

Meier, E. P., \& Gray, J. (2014). Facebook photo activity associated with body image disturbance in adolescent girls. Cyberpsychology, Behavior, and Social Networking, 17(4), 199-206. http://dx.doi.org/10.1089/cyber.2013.0305

Mills, J. S., Musto, S., Williams, L., \& Tiggemann, M. (2018). "Selfie" harm: Effects on mood and body image in young women. Body Image, 27, 86-92. http://dx.doi.org/10.1016/j.bodyim.2018.08.007 
Moher, D., Liberati, A., Tetzlaff, J., Altman, D. G., \& The PRISMA Group. (2009). Preferred reporting items for systematic reviews and meta-analyses: The PRISMA statement. Journal of Clinical Epidemiology, 62(10), 10061012. https://doi.org/10.1136/bmj.b2535

Morgan, J. F., Reid, F., \& Lacey, J. H. (1999). The SCOFF questionnaire: Assessment of a new screening tool for eating disorders. BMJ, 319(7223), 1467-1468. http://dx.doi.org/10.1136/bmj.319.7223.1467

Morgan, R. L., Whaley, P., Thayer, K. A. \& Schünemann, H. J. (2018). Identifying the PECO: A framework for formulating good questions to explore the association of environmental and other exposures with health outcomes. Environment International, 121(Part 1), 1027-1031. http://dx.doi.org/10.1016/j.envint.2018.07.015

Murray, M., Maras, D., \& Goldfield, G. S. (2016). Excessive time on social networking sites and disordered eating behaviors among undergraduate students: Appearance and weight esteem as mediating pathways.

Cyberpsychology, Behavior, and Social Networking, 19(12), 709-715. http://dx.doi.org/10.1089/cyber.2016.0384

Napolitano, F., Bencivenga, F., Pompili, E., \& Angelillo, I. F. (2019). Assessment of knowledge, attitudes, and behaviors toward eating disorders among adolescents in Italy. International Journal of Environmental Research and Public Health, 16(8), Article 1448. http://dx.doi.org/10.3390/ijerph16081448

Pantic, I. (2014). Online social networking and mental health. Cyberpsychology, Behavior, and Social Networking, 17(10), 652-657. http://dx.doi.org/10.1089/cyber.2014.0070

Pertegal-Vega, M. Á., Oliva-Delgado, A., \& Rodríguez-Meirinhos, A. (2019). Systematic review of the current state of research on Online Social Networks: Taxonomy on experience of use. Comunicar, 27(60), 81-91.

http://dx.doi.org/10.3916/C60-2019-08

Pew Research Center. (2019). Social Media Fact Sheet. Retrieved January 4, 2020 from

https://www.pewresearch.org/internet/fact-sheet/social-media/

Pike, K. M., \& Dunne, P. E. (2015). The rise of eating disorders in Asia: A review. Journal of Eating Disorders, 3, Article 33. https://doi.org/10.1186/s40337-015-0070-2

Probst, M., Vandereycken, W., Van Coppenolle, H., \& Vanderlinden, J. (1995). The Body Attitude Test for patients with an eating disorder: Psychometric characteristics of a new questionnaire. Eating Disorders, 3(2), 133-144. http://dx.doi.org/10.1080/10640269508249156

Quick, V. M., \& Byrd-Bredbenner, C. (2014). Disordered eating, socio-cultural media influencers, body image, and psychological factors among a racially/ethnically diverse population of college women. Eating Behaviors, 15(1), 37-41. http://dx.doi.org/10.1016/j.eatbeh.2013.10.005

Quiroz, S. I., \& Mickelson, K. D. (2021). Are online behaviors damaging our in-person connections? Passive versus active social media use on romantic relationships. Cyberpsychology: Journal of Psychosocial Research on Cyberspace, 15(1), Article 1. https://doi.org/10.5817/CP2021-1-1

Rodgers, R. F. (2016). The relationship between body image concerns, eating disorders and internet use, part II: An integrated theoretical model. Adolescent Research Review, 1, 121-137. https://doi.org/10.1007/s40894-0150017-5

Santarossa, S., \& Woodruff, S. J. (2017). \# SocialMedia: Exploring the relationship of social networking sites on body image, self-esteem, and eating disorders. Social Media+ Society, 3(2).

http://dx.doi.org/10.1177/2056305117704407

Saunders, J. F., \& Eaton, A. A. (2018). Snaps, selfies, and shares: How three popular social media platforms contribute to the sociocultural model of disordered eating among young women. Cyberpsychology, Behavior, and Social Networking, 21(6), 343-354. http://dx.doi.org/10.1089/cyber.2017.0713 
Schaumberg, K., Welch, E., Breithaupt, L., Hübel, C., Baker, J. H., Munn-Chernoff, M. A., Yilmaz Z., Ehrlich, S., Mustelin, L., Ghaderi, A., Hardaway, A., Bulik-Sullivan, E. C., Hedman, A. M., Jangmo, A., Nilsson, I. A. K., Wiklund, C., Yao, S., Seidel, M., \& Bulik, C. M. (2017). The science behind the Academy for Eating Disorders' nine truths about eating disorders. European Eating Disorders Review, 25(6), 432-450. http://dx.doi.org/10.1002/erv.2553

Schilder, P. (1950). The image and appearance of the human body. International Universities Press.

Slater, A., \& Tiggemann, M. (2015). Media exposure, extracurricular activities, and appearance-related comments as predictors of female adolescents' self-objectification. Psychology of Women Quarterly, 39(3), 375-389. http://dx.doi.org/10.1177/0361684314554606

Šmahelová, M., Čevelíček, M., Nehybková, E., Šmahel, D., \& Čermák, I. (2019). Is it important to talk about technologies with eating disorder clients? The health-care professional perspective. Health Communication, 34(1), 31-38. https://doi.org/10.1080/10410236.2017.1384354

Soh, N. L.-W., \& Walter, G. (2013). Publications on cross-cultural aspects of eating disorders. Journal of Eating Disorders, 1, Article 4. https://doi.org/10.1186/2050-2974-1-4

Sowles, S. J., McLeary, M., Optican, A., Cahn, E., Krauss, M. J., Fitzsimmons-Craft, E. E., Wifley, D. E., \& CavazosRehg, P. A. (2018). A content analysis of an online pro-eating disorder community on Reddit. Body Image, 24, 137144. http://dx.doi.org/10.1016/j.bodyim.2018.01.001

Statista. (2020). The statistics portal. Web site: Número mundial de usuarios de redes sociales 2016-2021. Retrieved January 7, 2020, from https://es.statista.com/estadisticas/512920/numero-mundial-usuarios-redes-sociales/

Statista. (2021). The statistics portal. Global social network penetration rate as of January 2021, by region. Retrieved March 8, 2021, from https://www.statista.com/statistics/269615/social-network-penetration-by-region/

Stice, E., Marti, C. N., \& Durant, S. (2011). Risk factors for onset of eating disorders: Evidence of multiple risk pathways from an 8-year prospective study. Behaviour Research and Therapy, 49(10), 622-627.

http://dx.doi.org/10.1177/0361684314554606

Tan, T., Kuek, A., Goh, S. E., Lee, E. L., \& Kwok, V. (2016). Internet and smartphone application usage in eating disorders: A descriptive study in Singapore. Asian Journal of Psychiatry, 19, 50-55.

http://dx.doi.org/10.1016/j.ajp.2015.11.007

Tao, X., Huang, W., Mu, X., \& Xie, H. (2016). Special issue on knowledge management of web social media. Web Intelligence, 14(4), 273-274. https://doi.org/10.3233/WEB-160343

Thelen, M. H., Farmer, J., Wonderlich, S., \& Smith, M. (1991). A revision of the Bulimia Test: The BULIT-R. Psychological Assessment: A Journal of Consulting and Clinical Psychology, 3(1), 119-124.

http://dx.doi.org/10.1037/1040-3590.3.1.119

Thompson, J. K., Burke, N. L., \& Krawczyk, R. (2012) Measurement of body image in adolescence and adulthood. In T. F. Cash (Ed.), Encyclopedia of body image and human appearance (pp. 512-520). Academic Press. https://doi.org/10.1016/B978-0-12-384925-0.00081-X

Tiggemann, M., Hayden, S., Brown, Z., \& Veldhuis, J. (2018). The effect of Instagram "likes" on women's social comparison and body dissatisfaction. Body Image, 26, 90-97. https://doi.org/10.1016/j.bodyim.2018.07.002

Tiggemann, M., \& Slater, A. (2014). NetTweens: The Internet and body image concerns in preteenage girls. The Journal of Early Adolescence, 34(5), 606-620. http://dx.doi.org/10.1177/0272431613501083

Tiggemann, M., \& Slater, A. (2017). Facebook and body image concern in adolescent girls: A prospective study. International Journal of Eating Disorders, 50(1), 80-83. http://dx.doi.org/10.1002/eat.22640 
Tiggemann, M., Slater, A., Bury, B., Hawkins, K., \& Firth, B. (2013). Disclaimer labels on fashion magazine advertisements: Effects on social comparison and body dissatisfaction. Body Image, 10(1), 45-53.

http://dx.doi.org/10.1016/j.bodyim.2012.08.001

van den Berg, P., Thompson, J. K., Obremski-Brandon, K., \& Coovert, M. (2002). The tripartite influence model of body image and eating disturbance: A covariance structure modeling investigation testing the mediational role of appearance comparison. Journal of Psychosomatic Research, 53(5), 1007-1020. http://dx.doi.org/10.1016/s00223999(02)00499-3

Walker, M., Thornton, L., De Choudhury, M., Teevan, J., Bulik, C. M., Levinson, C. A., \& Zerwas, S. (2015). Facebook use and disordered eating in college-aged women. Journal of Adolescent Health, 57(2), 157-163.

http://dx.doi.org/10.1016/j.jadohealth.2015.04.026

Westmoreland, P., Krantz, M. J., \& Mehler, P. S. (2016). Medical complications of anorexia nervosa and bulimia. The American Journal of Medicine, 129(1), 30-37. https://doi.org/10.1016/j.amjmed.2015.06.031

Worell, J., \& Todd, J. (1996). Development of the gendered self. In L. Smolak, R. H. Striegel-Moore, \& M. P. Levine, (Eds.), The developmental psychopathology of eating disorders: Implications for research, prevention, and treatment (pp. 135-156.). Routledge.

World Health Organization. (2019). Press release adolescent mental health. https://www.who.int/es/newsroom/fact-sheets/detail/adolescent-mental-health

Yan, Y., \& Bissell, K. (2014). The globalization of beauty: How is ideal beauty influenced by globally published fashion and beauty magazines? Journal of Intercultural Communication Research, 43(3), 194-214.

http://dx.doi.org/10.1080/17475759.2014.917432

Yellowlees, R., Dingemans, A. E., Veldhuis, J., \& de Vaate, A. J. D. B. (2019). Face Yourself(ie): Investigating selfiebehavior in females with severe eating disorder symptoms. Computers in Human Behavior, 101, 77-83.

http://dx.doi.org/10.1016/j.chb.2019.07.018 
Correspondence to:

Carmen Verde-Diego

Faculty of Education and Social Work

Doutor Temes

Ourense, 32004

Spain

Email: carmenverde(at)uvigo.es

Editorial record: First submission received on December 3, 2020. Revisions received on April 19, 2021 and May 19, 2021. Accepted for publication on May 21, 2021.

Editor in charge: David Smahel

\section{About Authors}

Paula Frieiro Padín, M.Sc., is a Ph.D. student and pre-doctoral fellow in the Department of Psycho-socioeducational Analysis and Intervention, at the University of Vigo.

Rubén González-Rodríguez, Ph.D. University of Santiago de Compostela and University of A Coruña, is a lecturer and researcher in the Department of Psychosocial and Educational Analysis and Intervention at the University of Vigo.

Carmen Verde-Diego, Ph.D. University of Santiago de Compostela, is a full professor and researcher in the Department of Psychosocial and Educational Analysis and Intervention at the University of Vigo.

Raquel Vázquez-Pérez, Ph.D. University of Vigo, is a lecturer and researcher in the Department of Psychosocial and Educational Analysis and Intervention at the University of Vigo.

(c) Author(s). The articles in Cyberpsychology: Journal of Psychosocial Research on Cyberspace are open access articles licensed under the terms of the Creative Commons BY-NC-ND 4.0 International License which permits unrestricted, non-commercial use, distribution and reproduction in any medium, provided the work is properly cited. 